\title{
Three down, three to go!
}

\author{
Lloyd R Sutherland MD FACP FRCPC
}

$\mathrm{J}$

ust three years ago I had the privilege and honor of becoming the third Editor-in-Chief of The Canadian Journal of Gastroenterology, the first to be appointed after Alan Thomson and Noel Williams stepped down as Founding Editors. As one ages time seems to fly and December 31, 2005, the end of my term, doesn't seem that far away.

The highlights of the past three years include the recognition of the journal as the official journal of the Canadian Association for the Study of the Liver. The Canadian Association of Gastroenterology (CAG) has established a publication committee, chaired by Keith Sharkey, that will conduct, among other duties, the selection of the fourth Editor-in-Chief for 2006. In conjunction with the CAG we surveyed the membership and found that you favour the publication of original Canadian research and clinical reviews. Based on the survey we have featured the publication of highlights of the Controversies in Gastroenterology as well as the Toronto Endoscopy Course. We would welcome submission of papers from other symposia across Canada.

In conjunction with Pulsus Group Inc. we have established an annual award for best paper (the Thomson/Williams Award). The first recipient was Dr Robin McLeod (1). The winner of the 2002 award will be announced at the CDDW in Banff, Alberta.

New sections, Canadian Gastroenterology Elsewhere and Hot Topics in Gastroenterology, have been piloted and will return in 2003. In support of the membership's maintenance of competence requirements, we have introduced a monthly quiz based on the contents of each issue.
So at this midpoint in my career as Editor-in-Chief what do I see as the challenges and opportunities ahead? The impact factor is a commonly used criterion of excellence for journals. Simply put, it is the number of times journal articles are cited by other journals, divided by the number of review articles and original papers we publish each year.

Over the past three years the impact factor of the The Canadian Journal of Gastroenterology has risen and we sit solidly in the middle third of the listings of 45 recognized journals focusing on gastroenterology. Where should we be and how can we reach that goal?

I believe that we should benchmark ourselves against the American Journal of Gastroenterology. As a national journal with an impact factor of 3.549 to our 1.368 , achieving parity will be a challenge but with your help it is attainable. To achieve this goal we will require greater support from the Canadian investigator community. They can provide additional original articles as well as contribute more reviews.

As Editor-in-Chief I am supported by Vicky Roubekas, the Associate Editors, the Editorial Board, reviewers and the staff at Pulsus Group Inc. Without their support none of this would be possible. I look forward to their ongoing support as we enter the second half of my term.

\section{REFERENCES}

1. McLeod RS. Screening strategies for colorectal cancer: A systematic review of the evidence. Can J Gastroenterol 2001 15:647-60. 


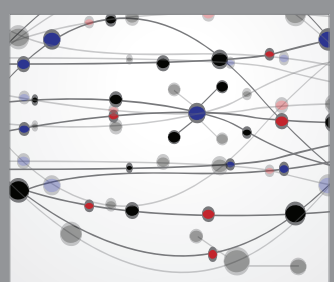

The Scientific World Journal
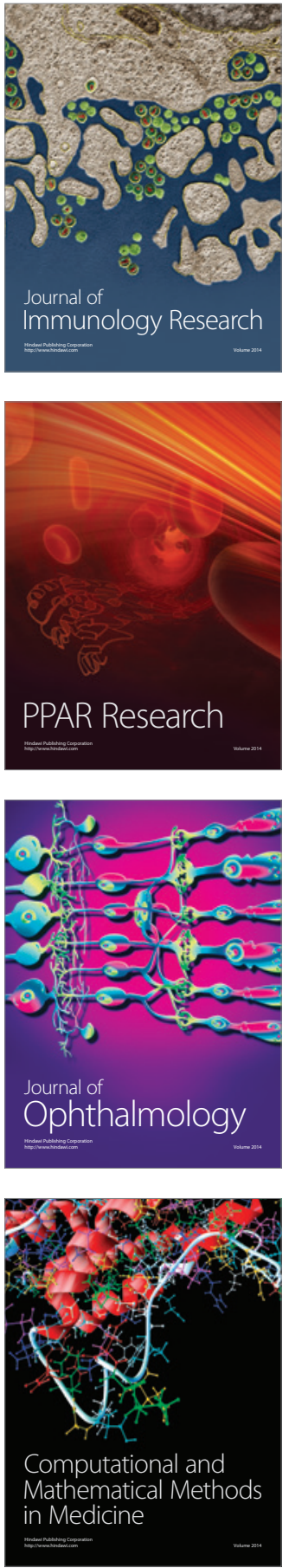

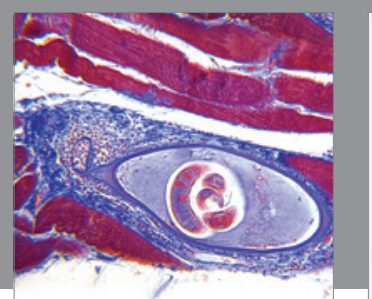

Gastroenterology Research and Practice

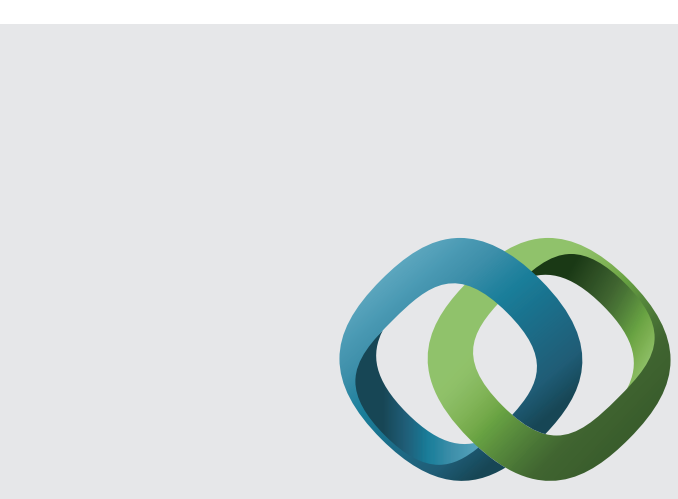

\section{Hindawi}

Submit your manuscripts at

http://www.hindawi.com
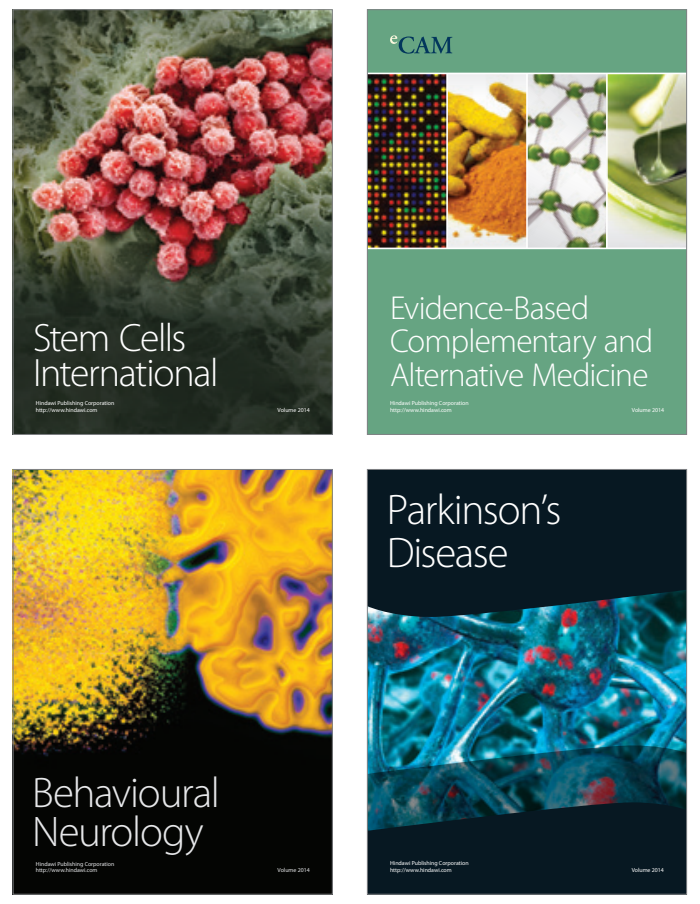
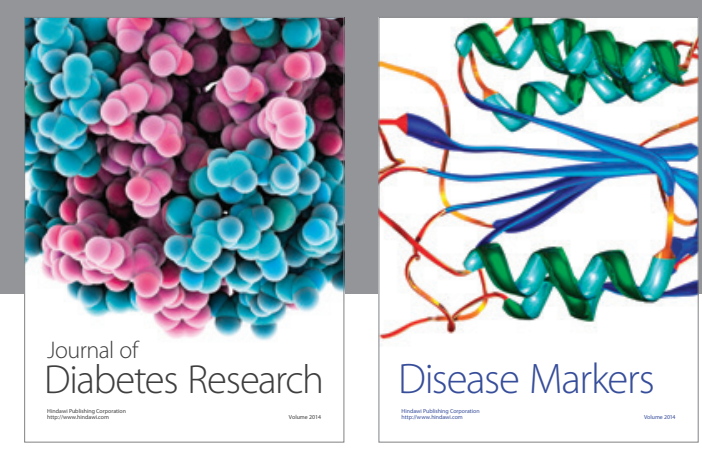

Disease Markers
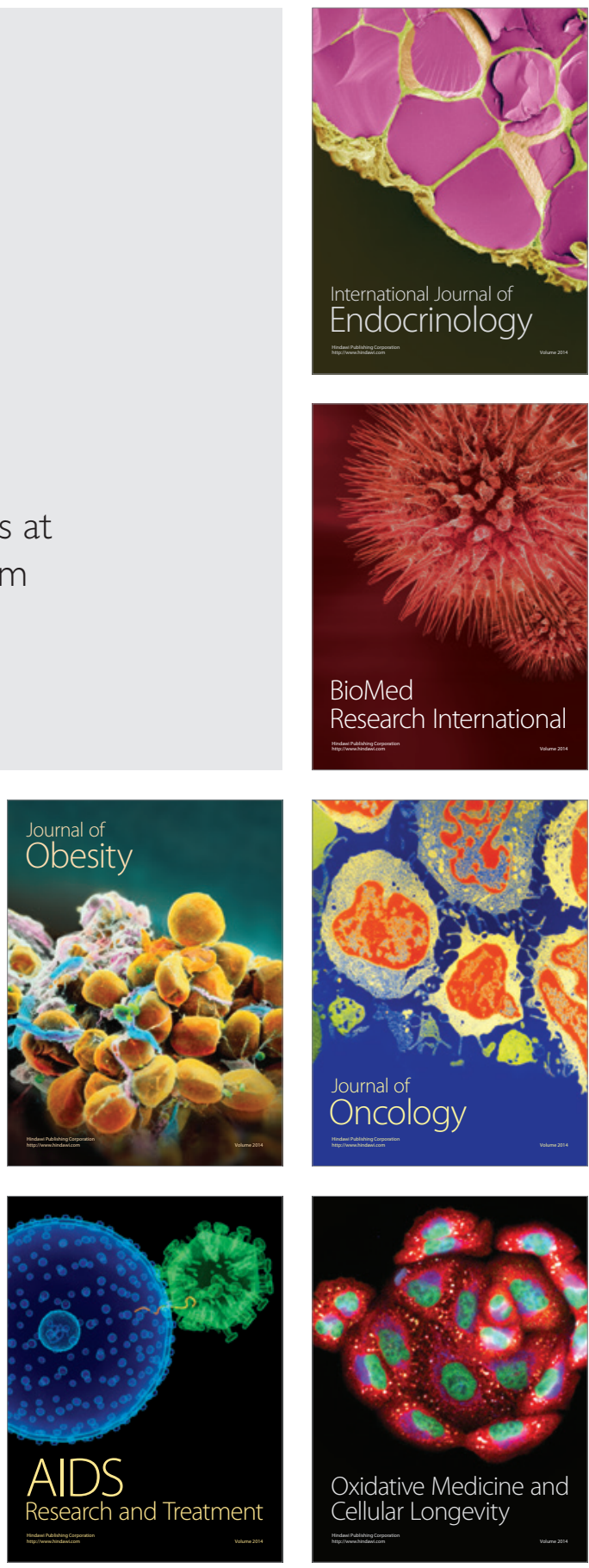